Creating Productive and Upcoming Sport Education Profesional Hmzanwadi University

Vol.4, No.1, Juni 2021, Hal. 39-44

e-ISSN 2614-8781

\title{
MODEL PEMBELAJARAN OLAHRAGA REKREASI
}

\author{
Kristoforus Ado Aran 1 \\ email: kristoaran86@gmail.com \\ ${ }^{1}$ Program studi pendidikan jasmani keseharan dan reakreasi Institut keguruan dan teknologi \\ larantuka
}

\begin{abstract}
Abstrak
Tujuan dari penelitian ini adalah menguji dan merumuskan model pembelajaran olahraga rekreasi. Metode yang digunakan adalah penelitian dan pengembangan (R\&D), dengan menggunakan model pembelajaran Contekstual Teacing and Learning (CTL). Data kualitatif dikumpulkan melalui pengembangan instrument dan observasi. Selain itu data juga dikumpulkan melalui wawancara, dosen pengamat dan diskusi dengan dosen lain setelah pelaksanaan model. Data dikumpulkan dalam bentuk catatan di lapangan, catatan diskusi dan wawancara, kemudian dianalisis sesuai dengan kategori berdasarkan kerangka konseptual. Selanjutnya data dianalisis melalui triangulasi, meliputi; (1) observasi, (2) ketekunan pengamatan,(3) pemeriksaan sejawat, dan (4) pengecekan anggota melaui diskusi.nhasil dari penelitian ini adalah bahwa nilai - nilai fair play, kepemimpinan, dan kreativitas telah diidentifikasi sebagai model, meskipun masih merupakan kecendrungsan, semua indicator muncul dalam kuliah olahraga rekreasi.
\end{abstract}

Kata Kunci: Olahraga Rkreasi, Kepemimpinan, Kreativitas, fair play, CTL

\section{Abstrack}

The purpose of this study was to test and formulate a recreational sports learning model. The method used is research and development $(R \& D)$, using the Contextual Teacing and Learning (CTL) learning model. Qualitative data were collected through instrument development and observation. In addition, data was also collected through interviews, lecturer observers and discussions with other lecturers after the implementation of the model. Data were collected in the form of notes in the field, notes on discussions and interviews, then analyzed according to categories based on the conceptual framework. Furthermore, the data were analyzed through triangulation, including; (1) observation, (2) persistence of observation, (3) peer examination, and (4) member checking through discussion. The result of this study is that the values of fair play, leadership, and creativity have been identified as models, although they are still trend, all indicators appear in recreational sports lectures.

Keywords: Recreational Sports, Leadership, Creativity, fair play, CTL

\section{A. Pendahuluan}

Fakultas Keguruan dan ilmu pendidikan (FKIP) Institut Keguruan dan Teknologi Larantuka memiliki program studi pendidikan jasmnai kesehatan dan rekreasi, salah satu mata kuliah disajikan dalam kurikulum adalah pendidikan olahraga rekreasi yang bertujuan membekali mahasiswa dengan pengetahuan teori dan praktek dilapangan hal-hal yang berhubungan dengan kegiatan rekreasi. Pelaksanaan pembelajaran matakuliah olahraga rekreasi di FKIP IKTL dirasakan kurang maksimal, ini dapat terlihat dari interaksi dalam proses perkuliahan yang monoton dan perpusat pada dosen sebagai satu - satunya sumber informasi, mahasiswa cendrung pasif dan hanya menerima pengetahuan dari dosen yang bersangkutan. 
Situasi ini mendorong peneliti untuk mengembangkan model pembelajran olahrag rekreasi yang mampu mengakomodasi tujuan perkuliahan serta menciptakan serta menciptakan situasi dan kondisi pembelajaran berjalan menjadi menyenangkan, tidak terpusat pada dosen, mendorong mahasiswa beriteraksi satu sama lainya dalam hail menananmkan nilai-nilai fair play yang merupakan ciri olahraga, perilaku kepemimpinaan, serta merangsang kreativitas mahasiswa untuk beriteraksi serta menuangkan ide-ide menciptakan jenis;jenis permainan olahraga rekreasi dalam bentuk kreativitas. Berdasarkan pemikiran tersebut di atas maka dikembangkan model CTL dalam kuliah olahraga Rekreasi.

Pemilihan model pembelajaran tersebut berdasarkan pada analisis peneliti sebagai tim dosen perkuliahan olahra rekreasi, bahwa penerapan model pembelajaran CTL merupakan konsep belajar yang membatu dosen mengaitkan antara materi yang diajarkannya dengan situasi dunia nyta mahasisiwa dan mendorong mahasiswa membuat hubungan antara pengetahuan yang dimilikinya dengan penerapannya dalam kehidupan mereka sehari-hari. Relevansi pemberian tempat bagi pembentukan nilai-nilai fair play, perilaku kepemimimpinan dan kreativitas yang dapat mendapat menumbuhkan pemahaman akan nilai-nilai yang terkandung dalam olahraga rekreasi. Hasil akhir dari pemanfaatan tiga variable ini adalah terbentuknya pemahamana nilainilai yang terkandung dalam olahraga terutama olahraga rekreasi, karena pada dasarnya proses pembelajaran yang dimaksudkan untuk mendorong, memunculkan perubahan tingkah laku yang lebih baik dari relative permanen. Beberapa ahli pendidikan seperti Jhon Dewey, Cllorence berpendapat bahwa di dalam rekreasi terdapat unsur-unsur permaninan, sehingga orang yang sedang berekreasi dikatakan main.untuk memberikan kejelasan tentang teori bermaian, Elmemer Mitchell dalam tulisan bukunya yang berjudul "The Theory of Play. Yang terdapat dalam buku "Rekreasi Terarah untuk pemuda", (Direktorat Jendral Olahraga dan Pemuda Departeman P dan $\mathrm{K}$, 2006) yaitu: (1) Teori kelebihan tenaga (the surplus energy thery); (2) Teori Rekreasi (the Recreatin theory); (3) teori gerakan insting (the instinc perticale theory); (4) teori rekapitulasi (rekapitulatin theory).

Rekreasi adalah kegitan yang dikerjakan oleh seseorang atau secara bersama- sama dengan orang lain, dalam waktu senggang (luang) secara sadar serta sukarela untuk mendapatka kesenangan, kepuasan serta kesegaran pribadi dengan secara langsung dan segera Alfina, I. (2013). Untuk menganalisa perumusan diatas dapat ditarik kesimpulan dan sekaligus dikemukakan mengenai ciri-ciri dari pada rekreasi oleh (Ramsay, 2005) Rekreasi adalah sutau aktivitas atau kegiatan yang bersifar fisik, mental maupun emosionalyang dialakukan pada waktu senggang dan didorong oleh keingginan atau motif atau bentuk dan macam aktivitas, dilakukan secara bebas, tanpa paksaan, yang disadari oleh diri sendiri secara sukarela, yang bersifat universal, kegiatan rekreasi tersebut semata-mata ingin mendapatkan kepuasan atau ketnangan. Rekreasi merupakan suatu aktivitas yang dilakukan pada masa senggang yang dilakukan tanpa paksaan, kegitan tersebut semata-mata ingin mendapatkan kepuasan dan kesenagna. Rekreasi merupakan aktivitas pengisian waktu senggang (Mallen dan Adams, 2008). Kegitan rekreasi harus bebrbentuk sesuatu yang sudah kita kenal umpamamnya olahraga, kesenian , kerajinanan tangan, seni drama, seni tari atau acara istimewa lainnya. Dengan yujuan yang ingin hendak dicapai yaiti memberi kesenangan, kepuasaan dan memupuk persaudaraan meredahkan ketegangan, mengisis kekosongan dan kesepian.

Rekreasi merupakan hal yang paling penting dan menjadi kebutuhan setiap individu. Setiap orang ingin mendapatkan kesenangan, kepuasan dan ingin menghilangkan ketegangan ketegangan baik baik ketegangan fisik maupun ketegangan mental. Kesemauan itu dapat diperoleh melalui kegiatan rekreasi yang sesuai dengan pilihan masing-masing. Rekreasi adalah 
kegiatan aktif dan pasif yang dilakukan dengan bebas dan kreatif dalam waktu senjang sebagai selingan pekerjaan sehari-hari sesuai dengan bakat dan kegemaranyayang menimbulkan kegembiraan dan kepuasan untuk memperoleh keseimbangan kesegaran fisik dan mental (Jennings, 2007). Manusia hidup pada dasarnya memerlukan olahraga, agar tubuh tetap sehat dan tidak mudah terserang oleh penyakit. Olahraga yang teratur mampu mengembangkan kondisi tubuh kembali dalam keadaan segar setelah melakukan aktivitas setiap hari yang melelahkan. Olahraga merupakan suatu kegiatan manusia dan olahraga mempunyai pengaruh terhadap pribadi pelakunya, hal ini telah dikemukakan oleh Bangun, S. Y. (2016) yang menyatakan bahwa olahraga adalah kegiatan jasmani atau kegiatan fisik manusia yang berpengaruh terhadap kepribadian dari pelakunya, sudah barang atau kegiatan fisiknya dalam olahraga adalah kegiatan yang menuntut kesanggupan jasmaniah tertentu untuk menggunakan tubuh secara menyeluruh.

Defenisi lain tentang olahraga juga dikemukakan oleh Motohir ( 2002 ) yang menyatakan bahwa olahraga adalah proses sistimik yang berupa sega kegiatan atau usaha yang dapat mendorong, membangkitkan, mengembnagkan, dan membina potensi jasmaniah dan rohaniah sesorang sebagai perorantan atau sebagai anggota masyarakat dalam bentuk permainan, perlombaan atau pertandingan, dan kegiatan jasmani yang intensif untuk memperoleh reakreasi, kemenagna, dan potensi puncak dalam rangka pembentukan manusia Indonesia seuutuhnya yang berkualitas berdasarkan pancasila. Olahraga dapat mempengaruhi kehidupan seseorang, karena kehidupan seseorang sangat dipengaruhi oleh fisik, psikologis dan social, hal ini sesuai dengan dasar-dasar olahraga yang dikemukakan oleh Horne (2005) yaitu: (1) Olaharaga bersifat Fisik, artinya pertumbuhan fisik yang harmonis yaitu pengearuh yang sangat baik bagi pertumbuhan otot-otot, peredaran darah, pernapasan, pencernaan, reaksi dan sebagainya; (2) Olahraga bersifat rohani, seperti keberanian, ketekunan hati, percaya pada diri sendiri atau pada orang lain, jujur dan lain-lain; (3) Olahraga bersifat sisologis, artinya olahraga memberikan kesempatan memperbanyak pergaulan dan mengoisi waktu luang.

Olahraga rekreasi sendiri muali dari Inggris ketika para tuan tanak banyak seaki memiliki waktu luang dan mengisi dengan aktifitas fisik dihalaman istana yang luas. Maka terciptalah olahraga rekreasi yang dikenal di Eropa dengan aksi trim, di Amerika dikenal dengan Recrational sport, dan biasanya dengan istilah umum disebut " Sport for All"

\section{B. Metode}

Penilaian ini bertujuan mengembangkan dan mengujicobakan model pembelajaran olahraga rekrasi dengan model pembelajaran CTL dalam upaya pembentukan nilai-nilai fair play, kepemimpinan, dan kraetivitas. Model penilaian yang digunakan adalah penelitian dan pengembangan (research and development). Subyek dalam penelitian ini adalah mahasiswa Program studi PJKR IKTL yang mengambil matakuliah olahraga rekreasi pada semester genap tahun akademik 2020/2021. Tahapan dan siklus model disusun menjadim: (1) merumuskan model teoritis; (2) mendapatkan data dasar; (3) melakukan uji coba; (4) merevisi model perkuliahan dan instrument; (5) dimensi produk. Instrument pengumpulan data yang digunakan adalah peneliti sendiri, camera, obsevasi yang dugunakan oleh dosen. Oleh karena iti data berupa kualitatif maka digunakan paradigm kualitatif yang lebih menekankan pemahaman. Untuk menangkap makna dari sudut pelaku melalui pengamatan. Adapun langkah analisi adalah: (1) mengumpulkan seluruh data dari hasil pengamatan; (2) melakukan analisis berupa catatan lapangan, catatan wawancara dan catatan diskusi; (3) melakukan proses sintesis yaitu mengelolah keseluruhan data masing- masing kategori; (4) membuat kesimpulan akhir. 


\section{Hasil dan Pembahasan}

Hasil penelitian ini merupakan hasil anlisis data yang didapat selama penelitian berlangsung. Semua data merupakan data kualitatif. Data itu terdiri dari 16 catatan lapangan 40 lembar observasi, 2 catatan wawancara, 2 catatan diskusi, rangkuman dosen sejawat. Untuk menjaga keabsaan data dilakuakan hal-hal berikut: (1) ketekunan penelitian, dengan melakukan 16 kali pengamatan yang melibatkan 2 dosen pengamat yang menggunakan lembaran observasi, juga dilakukan pengambilan gambar; (2) Triangulasi, dengan cara wawancara ketua program studi PJKR FKIP IKTL, serta 2 dosen teman sejawat

Pembahasan

Nilai - nilai Fair Play

Nilai -nilai Fair Play dalam perkuliahan olahraga rekreasi ditumbuhkan melalui penetapan CTL dengan cara memberikan peluang kepada mahasiswa dalam seluruh proses perkuliahan untuk bermain, berkopetisi, bekerja sama, saling menilai, saling menghargai, menerapkan nilai-nilai kejujuran, persahabatan, rasa hormat, dan tanggung jawab, sekaligus diberi kesempatan untuk mengakui keunggulan temannya. Secara langsung ini juga berarti melatih mahasiswa untuk mau menerima kelemahan atau kekurangan diri sendiri. Tetapi semua itu dialami dalam suasana perkulihan yang penuh keceriaan, menyenangkan dan melibatkan seluruh mahasiswa. Kompetisi yang dialakukan dalam perkuliahan oalhraga rekreasi dilakukan dalam suasana yang menyenagkan dan penuh kompetititf. Penentu siapa pemenag dilakukan oleh mahasiswa bukan dosen. Setiap kali ada penentuan kelompok yang baik, mahasiswa yang diminta untuk menentukan dengan terlebih dahulu menetapkan indicator penilaian. Hal ini sengaja dilakukan agar mahasiswa sungguh mengalami sendiri bagaimana rasanya mengakui kekalahan, megakui kelebihan orang lain, dan kelemahan diri sendiri, atau sebaliknya secara nyta.

Kepemimpinaan.

Perilaku kepemimpinan dalam perkuliahan olahraga rekreasi ditumbuhkan melalui penetapan CTL dengan cara memberikan peluang kepada mahasiswa untuk mengembangkan kecerdasan dan kemampuan yang baik. Dalam perkuliahan mahasiswadibiasakan harus cakap dalam memimpin. Kecakapan dan kecerdasan ini tumbuh melalui diskusi, mahasiswa bukan saja dilatih mengemukkan pendapatnya, tetapi sekaligus dilatih untuk menuangkan idi- ide dalam memprosentasekan jenis- jenis olahraga rekreasi yang baru yang belum ada sebelumnya.

Kreativitas

Perkuliahan olahraga rekreasi menuntut suatu kreativitas yang sangat tinggi. Kreativitas tersebut merupakan hal yang sangat penting untuk dilakukan dan dibahas, mengiat dalam semua proses perkuliahan baik yang dilakukan diberbagai tempat baik indoor maupun autdoor sehingga memungkinkan mahasiswa menuangkan ide-ide baru dalam menciptakan bentuk-bentuk olahraga rekreasi yang baru hasil modifikasi dari jenis-jenis olahraga prestasi, olahraga pendidikan, dan permainan tradisional. Bentuk kreativitas itu paling nyata tampak dan menonjol ketika para mahasiswa diberi kesempatan dalam suasana bebeas menentukan indikator penilaian utuk menilai keterampilan teman mereka dan menentukan cara memahami permainan olahraga rekreasi yang ditampilkan. Suasana yang bebas dan dialogis, kesetaraan mahasiswa dengan mahasiswa, mahasiswa dengan dosen, keterlibatan mahasiswa, adanya pemicu, pemanfaatan pengelaman mahasiswa dan apa yang diketahui oleh mahasiswa, sebagai narasumber selain 
dosen dan memberi peluang bagi mahasiswa untuk ikut menentukan telah terbukti dapat memicu kraetivitas siswa dalam perkuliahan. Kreativitas ditandai dengan berpikir lancar, berpikir luwes, berpikir orisinal, melihat dengan cara lain, berbagai pandangan dan pendekatan yang berbeda, membuat kombinasi dan pertalian baru serta pencarian alternative baru.

\section{Simpulan}

Pertama, model pembelajaran Contextual teaching learning (CTL) cocok untuk pengembangan model pembelajaran olahraga rekreasi yang mengintegrasikan pembentukan perilaku nilai-nilai fair paly, kepemimpinan dan kreativitas. Materi perkuliahan berupa teori dan praktik olahraga rekreasi baik yang dilakukan di alam terbuka, di dalam ruangan, gedung dan lapangan utnuk mendorong mahasiswa semakin memahami dan mengenal nilai-nilai yang terkandung di dalam olahraga rekreasi. Kedua, pengembangan model pembelajaran olahrag rekreasi yang mengitergrasikan pembentukan perilaku nilai-nilai fair play, kepemimpinan dan kreativitas, dilaksanakan dengan model pembelajaran CTL menekankan aktivitas yang bersifat interaktif. Secara singkat dapat disebutkan model ini disebut aktivitas interaktif bukan model materi. Model aktivitas interaktif menekankan pentingnya ketrlibatan secara aktif mahasiswa dan dosen dalam bebagai aktivitas interaktif dan membantu guru/dosen mengaitkan antar materi yang diajarkan dengan situasi dunia nyata dan mendorong mahasiswa mengaitkan antara pengetahuan yang dimiliki dengan penerapanya dalam kehidupan sehari-hari di lingkungan keluarga dan masyarakat. Ketiga, model pembelajaran CTL ini tampak efektif untuk membentuk nilai- nilai fair play, perilaku kepemimpinan dan kreativitas dalam perkulihan olahraga rekreasi, karena hamper semua indicator dan sub indicator muncul di dalam uji coba. Namun diakui kemunculan itu masih merupakan kecendrungan, belum merupakan perilaku yang tepat, mantap, melekat, dalam diri mahasiswa karena uji coba dilaksanakan dalam waktu yang relative singkat. Keempat, dalam penelitian ini dikembangkan tiga lemabar observasi untuk membentuk nilai-nilai fair play, perilaku kepemimpinan, krearivitas dalam perkuliahan olahraga rekreasi setiap lembar observasi itu digunakan dan terus dikembangkan. Tampaknya penggunana lembaran observasi dapat mencakup keseluruhan aspek dan bersifat lebih mendalam menilai keseluruhan indicator, sehingga penilaianya lebih komprehensop dan mendalam.

\section{Daftar Pustaka}

Ashiddiqie, M. H. (2020). Pendidikan Pengalaman Dalam Perspektif Pendidikan Islam. AlIlmu, 5 (2), 70-94.

Alfina, I. (2013). Manajemen Pengelolaan Fasilitas Outbound Objek Wisata Linggo Asri Sebagai Wahana Pendidikan Rekreasi Di Kabupaten Pekalongan Tahun 2013 (Doctoral Dissertation, Universitas Negeri Semarang).

Bangun, S. Y. (2016). Peran Pendidikan Jasmani Dan Olahraga Pada Lembaga Pendidikandi Indonesia. Publikasi Pendidikan, 6 (3).

Depdiknas., 2008. Pedoman Fair Play Olinpiade Olahraga Siswa Nasional I Sekolah Dasar Tahun 2008. Jakarta: Depdiknas.

Direktorat Jendral Olahraga dan Pemuda., 2008. Rekreasi Untuk Pemuda. Jakarta: Direktorat Jendral Olahraga dan Pemuda, Departemen P dan K.

Dan, P. D. D. S. P. (2017). Kebudayaan,". Statistik PAUD, 2018.

Fahrudin, F. A. (2017). Efektivitas Problem Based Learning Terhadap Kemampuan Berpikir Kreatif Mahasiswa Program Studi Tadris Matematika UIN Mataram. JTAM (Jurnal Teori dan Aplikasi Matematika), 1 (1), 41-48. 
Hera, T. (2018, July). Aspek-Aspek Penciptaan Tari Dalam Pendidikan. In Prosiding Seminar Nasional Program Pascasarjana Universitas Pgri Palembang (Vol. 5, No. 05).

Mutohir, T.C., 2002. Gagasan- gagasan Tentang Pendidikan Jasmani dan Olahraga. Surabaya: Unesa University Press.

Mulkhan, A. M. (2016). Islam di Tengah Konflik dalam Dinamika Perkembangan IPTEK dan Kebudayaan. Jurnal Bestari, (31).

Neisser, U. (2014). Psikologi kognitif: Edisi klasik . Pers Psikologi.

Nurfalah, Y. (2017). Mendidik Anak Supernormal dalam Perspektif Pendidikan Islam. Tribakti: Jurnal Pemikiran Keislaman, 28 (2), 217-245.

Petty, G., 2002. Creativite: Memaksimalkan Potensi Kreatif., diterjemahkan oleh Hari Wahyudi., Jakarta: PT. Elex Media Komputindo.

Ramsay, H., 2005. Reclaiming Leasure; Art, Sport, and Phylosophy. New York: Macmillan.

Rohayuningsih, H., \& Handoyo, E. (2015). Berpikir Kreatif dalam Pengambilan Keputusan. In Forum Ilmu Sosial (Vol. 42, No. 1, pp. 106-113).

Samples, B., 2002. Revolusi Belajar untuk Anak., diterjemahkan oleh Rahmani Astuti. Bandung : KAIFA.

Samsudin., 2008. PembelajaranPEndidikan Jasmani Olahraga dan Kesehatan. Jakarta : Litera Prenada Media Group.

Suherman, Y. (2014). Akselerasi-inklusi Dalam Perspektif Layanan Efektif Anak Berbakat. Perspektif Ilmu Pendidikan, 28(2), 157-163.

Solso, RL, MacLin, MK, \& MacLin, OH (2005). Psikologi kognitif. Pendidikan Pearson Selandia Baru. 